\title{
Estudio de la cognición ambiental infantil en la ciudad de Bogotá*
}

\section{A study of children's environmental cognition in Bogotá}

\author{
Jacqueline Benavides Delgado ${ }^{\circledR}$, Gilberto Oviedo Palomá ${ }^{\circledR}$
}

Para citar este artículo: Benavides, J., Oviedo, G. (2019). Estudio de la cognición ambiental infantil en la ciudad de Bogotá. Infancias Imágenes, 18(2). [171-183]

\section{Resumen}

El presente artículo aborda la representación mental infantil de un espacio urbano en Bogotá. La pregunta que orientó la investigación fue: ¿cómo se orientan espacialmente niños de diferente edad en un ambiente urbano? La hipótesis se basó en la teoría piagetana, que defiende como la orientación espacial sigue un proceso cognitivo de complejidad creciente que se inicia en la temprana infancia en estado de egocentrismo y tiende, con la maduración y el desarrollo, a la representación abstracta de la ciudad. La metodología de investigación consistió en la aplicación de mapas cognitivos a niños entre los 7 y 14 años que estudian en un espacio universitario. Los resultados demuestran la naturaleza constructivista de la cognición ambiental, pues la temprana infancia se orienta con base en elementos ambientales ligados a la interacción sensorio-motriz y tan solo en la pubertad se logran entender las relaciones entre los diferentes componentes urbanos de manera abstracta.

Palabras clave: cognición, espacio urbano, psicología ambiental, comportamiento urbano, ciudad.
Recibido: 30-09-2018 - Aceptado: 12-07-2019

\section{Abstract}

This article addresses the ways in which children create a mental representation of an urban space in Bogotá. The question guiding this research was: How are children of different ages spatially oriented within an urban environment? The hypothesis was based on Piaget's theory that asserts that spatial orientation follows a cognitive process of increasing complexity beginning at the early childhood stages in an egocentric state and expanding, with maturity and development, to an abstract representation of a city. The research methodology consisted of cognitive mapping of children between the ages of 7 and 14, studying in a university environment. The results exhibit the constructivist nature of environmental cognition. Early childhood is guided by environmental elements linked to the sensory motor interaction, and it is only with the onset of puberty that it becomes possible to understand the relationships between different urban components in an abstract manner.

Keywords: cognition, urban spaces, environmental psychology, urban behavior, city.

\footnotetext{
Algunos datos e imágenes provienen de la investigación "La orientación espacial de los niños en el espacio físico de la Universidad de los Andes", financiada por la Universidad de los Andes.

1 Doctora en Psicología. Profesora de la Universidad Cooperativa de Colombia. Investigadora del Grupo Boulomai. correo electrónico: jaqueline.benavidesd@campusucc.edu.co

2 Doctor en Historia. Profesor de la Pontificia Universidad Javeriana. Correo electrónico: goviedo01@ hotmail.com
} 


\section{Introducción}

La relación entre el niño y la ciudad es un tema novedoso en psicología, pues habitualmente se piensa el desarrollo infantil como un proceso individual aislado de las condiciones ambientales como el entorno urbano, al igual que el contexto físico y social. La ciudad y los espacios urbanos tienen una relación muy cercana con la calidad de vida, el bienestar de las personas y su desarrollo mental, pues, como lo afirma Proshansky:

Sorpresivamente no parece ocurrírsele a los psicólogos que parte de la variabilidad que puede estar involucrada en el concepto de autoestima [...] la ansiedad o tranquilidad en el confinamiento o incluso la productividad de los jóvenes... puede ser atribuido a la naturaleza, significado, diseño, organización y uso del espacio físico. (1984, p. 176)

La psicología ambiental ha sido el área disciplinar consagrada a estudiar las implicaciones psicosociales del fenómeno urbanístico (Aragonés y Amérigo, 1998). La creciente tendencia internacional y de la población colombiana a vivir en espacios urbanos invita a pensar sobre la forma en que el entorno citadino incide sobre la ciudadanía (ONU-Habitat, 2012). En particular, resulta de importancia la aproximación a la integración de las personas a la ciudad y su capacidad para usar recursivamente sus locaciones.

En Colombia se ha iniciado un reciente esfuerzo por abordar los temas de la psicología ambiental en el ámbito citadino: Gallego, Gallego, Arboleda, Garcés y Sepúlveda (2017) abordaron la influencia de la psicología ambiental en el contexto educativo. García y Peralta (2016) analizaron los espacios multifamiliares como forma de crecimiento urbano y su efecto sobre la relación de la ciudadanía con la ciudad. Jiménez e Infante (2008) abordaron las narrativas populares infantiles sobre la ciudad de Bogotá. Rizo, Gutiérrez y Granada (2004) se encargaron de investigar sobre las actitudes de responsabilidad ambiental en espacio universitario. Los textos citados se caracterizan por su interés en aplicar los fundamentos teórico-metodológicos de la psicología ambiental para atender problemas como la protección ambiental o el desarrollo social de poblaciones marginadas.

El presente estudio establece un contraste con las aproximaciones aplicadas de la psicología ambiental en Colombia, pues aborda la cognición ambiental infantil a través de un problema teórico: la orientación espacial en ambientes urbanos. Se hace, por tanto, necesario describir la trayectoria del problema de la comprensión del entorno citadino dentro de la psicología ambiental.

Los trabajos de los diseñadores urbanos del siglo XX, como Lynch (1998), asumen que un aspecto determinante de la relación del ciudadano con el entorno urbano es la orientación espacial. El hecho de que las personas comprendan su ambiente físico y puedan representar con fluidez la forma de desplazarse para satisfacer sus necesidades fundamentales, como acceder a un hospital o las entidades educativas o las zonas de recreación o abastecimiento, determina su capacidad de supervivencia, adaptación y bienestar. El hecho de estar perdido ha sido descrito por Lynch (1998) como una experiencia subjetiva de absoluto desastre, pues la persona desorientada experimenta un estado de desasosiego, miedo y sensación de inseguridad, así como una gran dificultad para planear y ejecutar recorridos urbanos. La desastrosa sensación de desorientación espacial se agrava si se piensa en la experiencia de los niños, quienes viven con especial dramatismo el hecho de perderse en la maraña urbana.

La desorientación espacial infantil suele combatirse en la mayoría de las ciudades con un elemental recurso: la reclusión de la infancia en sitios de permanente supervisión en medio de un continuo proceso de aislamiento del niño de la ciudad y dependencia de los cuidadores. La concepción de la calle como el enjambre de la maldad por sus riesgos de accidentabilidad, rapto, transgresión y abuso ha promovido los estudios sobre las condiciones amenazantes de la ciudad (Roncancio, Minsnaza y Prieto, 2015; Sotelo y Barrios, 2006). En pocos casos se considera a la ciudad como objeto de comprensión y entendimiento susceptible de ser usada recursivamente por la ciudadanía infantil, a través del aprendizaje de medidas autónomas de precaución y planeación (Tonucci, 1997, 1983, 2009). 
Más recientemente, se han realizado importantes esfuerzos por fortalecer la idea del niño como ciudadano que requiere de la experiencia urbana para desarrollar su comprensión del ambiente y su autoestima, al igual que sus facultades cognoscitivas. Algunos autores han demostrado que los niños que se desplazan entre la casa y la escuela de manera autónoma y peatonal desarrollaban una mejor comprensión de su ambiente, planeación de rutas y solución de problemas urbanos que los niños que se desplazan en vehículo o con la compañía de un adulto (Rissotto y Tonucci, 2002). En 2014, en Australia Foster, Villanueva, Wood, Christian y Giles-Corti realizaron un estudio sobre la relación entre el temor de los padres a los extraños y la movilidad e independencia en niños de 10-12 años. Los niños con mayor independencia para su movilidad urbana mostraron una mayor seguridad personal para tomar decisiones ambientales y hacer uso recursivo de la calle. Vidar, Vitaro, Brendgen y Borge (2017) analizaron la relación entre el desarrollo cognitivo, la atención y el tiempo que los niños pasan fuera de casa. Estos autores encontraron una correlación positiva entre el tiempo que los niños pasan fuera en la calle, o en la ciudad y un mayor desarrollo cognitivo y atencional.

Ante la consideración del niño como un sujeto desorientado espacialmente, por parte del sentido común, se abre la posibilidad científica de pensar al niño como ciudadano que se orienta de manera diferente a la de los adultos. El niño pasa a ser considerado, en la psicología ambiental, como un sujeto cognoscitivo que requiere de interactuar con el ambiente para desarrollar ideas propias sobre su entorno.

Una pregunta orienta el presente estudio: ¿cómo se orientan los niños de diferentes edades en el ambiente urbano? A su vez, vale la pena preguntarse sobre las alternativas y estrategias investigativas que favorecen la descripción de los procesos mentales en materia ambiental.

En primer lugar, es necesario mencionar la importante tradición desarrollada en la psicología ambiental sobre el concepto de cognición ambiental. La ciudad ha sido considerada como un objeto perceptual frente al cual el sujeto realiza un permanente proceso cognoscitivo de ordenamiento y administración de la información ambiental (Oviedo, 2002, 2006). El ordenador mental se caracteriza por la selección y extracción de estímulos urbanos para llevar a cabo procesos de almacenamiento, clasificación y creación de estados imaginativos como la planeación de las interacciones ambientales (Aragonés y Amérigo, 1998).

La orientación espacial es una actividad cognoscitiva caracterizada por la construcción de imágenes mentales. El sujeto frente al ambiente selecciona y sintetiza la enorme cantidad de datos ambientales a través de una pantalla visual, que guarda una gran semejanza con un mapa. La psicología ambiental asume que la forma en que se orientan las personas en el ambiente es a través de la estructuración de un mapa cognitivo, (Kitching, 2015; Montello, 2015; Miao, Zeng y Weber, 2017) el cual se define como: "un constructo que abarca aquellos procesos que hacen posible a la gente adquirir, codificar, recordar y manipular información acerca de la naturaleza de su ambiente espacial" (Downs y Stea, 1973, p. XIV).

El concepto de mapa cognitivo tiene en la psicología ambiental dos acepciones. Una de carácter teórico dirigida a ilustrar la tendencia del aparato mental a configurar imágenes mentales; y otra relacionada con el desarrollo de estrategias metodológicas dirigidas a describir la representación psíquica del ambiente. El mapa cognitivo como herramienta investigativa fue inaugurada por Lynch (1998) quien consideró que la imagen mental de la ciudad puede observarse de manera indirecta a través de la actividad gráfica. Sujetos desprevenidos fueron invitados por Lynch (1998) a dibujar un bosquejo del centro de algunas ciudades estadounidenses. La actividad gráfica resultó sumamente exitosa, pues las personas se sentían muy motivadas a plasmar en el papel los elementos ambientales que favorecen su orientación y mostraban a las claras las relaciones de dirección y distancia entre elementos referenciales. El dibujo de la ciudad resultó una forma espontánea y divertida de exponer la percepción que tienen las personas del ambiente urbano, incluidos los niños.

El estudio de la cognición ambiental infantil ha tenido un importante desarrollo investigativo, a través de la estrategia gráfica de mapa cognitivo. Uno de los temas más atractivos ha sido la evolución y 
transformación de los mapas cognitivos a lo largo de la vida (Caballero, 2002; Lázaro, 2000). Autores como Hart y Moore (1973) y Moore (1974) interpretaron la evolución de los mapas cognitivos infantiles a la luz de la teoría de Piaget (1973).

El constructivismo genético de Piaget resultó inspirador en materia de cognición ambiental, pues asume que el desarrollo cognoscitivo sigue un proceso de complejidad creciente que se inicia con el pensamiento egocéntrico y tiende hacia la descentración o desarrollo de la capacidad abstracta. Las etapas del desarrollo ontogenético de Piaget surtieron una interesante alternativa de exploración y clasificación de los mapas cognitivos en diferentes periodos del desarrollo ontogenético (Marchesi, 1983).

Los mapas cognitivos en etapas tempranas del desarrollo infantil se caracterizaron por sus rasgos egocéntricos, es decir, por la excesiva concentración infantil por los elementos ambientales más impresionantes desde el punto de vista sensorial.

174 Los elementos ambientales estruendosos, particularmente móviles, brillantes o de permanente interacción sensorio-motriz constituyen aspectos determinantes de los mapas cognitivos en etapas tempranas del desarrollo (Goga y Kümmerling-Meibauer, 2017; Miao, Zeng y Weber, 2017).

El rasgo egocéntrico de mayor protuberancia radicó en la diseminación de los elementos ambientales dibujados en el mapa cognitivo, pues carecen de coordinación espacial. Con frecuencia, los dibujos infantiles, en las etapas más tempranas del desarrollo cognoscitivo, resultan desarticulados en virtud de la tendencia a la superposición de elementos como sucede con los llamados "mamarrachos" o "matachos" en los que se retiñe sobre una forma ya dibujada o en la presentación de objetos sin conexiones gráficas, como pueden ser una serie de rayones dispersos en el papel (Hart y Moore, 1973). Se infiere de los datos arrojados por este tipo de mapas cognitivos que los niños, en periodos tempranos de desarrollo, perciben el ambiente como una serie de estímulos dispersos sumamente Ilamativos e impactantes, ante los cuales el niño se siente sorprendido y sin capacidad de contextualizarlos en un espacio o escenario urbano. El niño capta datos difusos y diseminados sin solución de continuidad espacial.

El desarrollo cognitivo sigue un proceso de superación del estado egocéntrico (en el que el niño está centrado en los objetos particulares) para abrirle camino al proceso de integración de las imágenes dispersas y descoordinadas del mapa cognitivo. Los niños en el periodo de edad escolar tienen los primeros intentos de coordinación espacial entre elementos, pero la persistencia del egocentrismo les impide salir del todo de la fascinación que ofrecen los objetos de frecuente interacción sensorio-motriz o de especial atracción sensorial. Con el nombre de mapas semicoordinados se designa a aquellos dibujos en los que el sujeto intenta articular de manera parcial los objetos, a través de conexiones gráficas e intenta salir de la yuxtaposición de objetos, es decir, matachos. Se procura en los mapas semicoordinados abandonar parcialmente las formas inconexas para acceder al manejo de relaciones de distancia y dirección, mediadas por elementos articuladores.

Se ha denominado con el nombre de mapas coordinados o abstractos a los dibujos propios de los niños del periodo puberal y adolescente. En los mapas coordinados se lleva a cabo un proceso de abstracción, pues el niño supera la fascinación por los objetos puntuales para volcarse sobre la consideración del ambiente como una totalidad en la que es posible establecer la relación entre la parte y el todo. Los objetos dibujados son ubicados dentro de un contexto más amplio. Así, por ejemplo, se tiende a mostrar el mapa configurado por un punto de partida y otro final, con estaciones intermedias que le muestran al observador diferentes elementos de enlace favorecedores de la orientación. En los mapas coordinados o abstractos el niño puede pensar en el otro y en su necesidad de encontrar elementos de referenciación espacial para realizar un recorrido ambiental.

En resumen, se puede afirmar que los niños se orientan espacialmente en el espacio urbano de acuerdo con su nivel de desarrollo cognitivo. La imagen mental del ambiente sufre una continua movilidad que transita de las formas egocéntricas al desarrollo de un proceso abstracto. 
La hipótesis que se someterá a comprobación se formula en los siguientes términos. Los niños de menor edad en periodo preescolar presentan una cognición ambiental caracterizada por la presencia de mapas egocéntricos. Los niños de edad escolar se caracterizan por la presencia de mapas semidiferenciados y los sujetos en edad puberal y adolescencia presentan mapas abstractos o coordinados. La orientación espacial en el ambiente urbano sigue un orden de complejidad creciente que se hace manifiesta en la capacidad de coordinar los elementos gráficos del mapa cognitivo, con el avance en la edad.

\section{Método}

La investigación constituye un estudio transversal, ya que se seleccionaron niños de diferentes edades que representan su grupo de edad. Se controlaron variables como familiaridad, escolaridad, desempeño académico y capacidad de dibujar con fluidez. Se abordó metodológicamente la cognición ambiental de los niños a través de la herramienta de mapas cognitivos, con un enfoque cualitativo, pues se hizo énfasis en la presencia o ausencia de conexiones gráficas entre objetos dibujados, así como su incremento o descenso en relación con la edad. De este modo, el estudio asumió como criterio de comprobación de la hipótesis la estrategia de determinar el incremento en las conexiones entre objetos percibidos con respecto a la edad.

\section{Participantes}

Los participantes fueron 7 niños con edades comprendidas entre los 4 y 14 años. Los niños asisten al mismo tiempo, con la misma frecuencia y con la misma antigüedad a una institución educativa universitaria de la ciudad de Bogotá, en la que aprenden música o practican deportes los días sábados. Est4e espacio guarda todas las características de un ambiente urbano y se constituye en sí misma en una ciudad universitaria. Se seleccionó este sitio, pues se trata de un escenario en el cual todos los sujetos se desplazan peatonalmente y allí realizan actividades académicas en el área de estudios musicales y deportes, lo cual implica el uso de locaciones, tiempos y actividades similares.

\section{Materiales}

Se utilizaron hojas en blanco lápices, borradores y tablas de madera sobre las cuales dibujar.

\section{Procedimiento}

La directriz verbal que se dio a los niños para realizar el mapa cognitivo fue la siguiente: "Un niño nuevo, de tu misma edad, va a entrar a estudiar contigo y necesita conocer este sitio para asistir a las clases. Por favor, haz un dibujo de la universidad, para ayudarlo a orientarse. No tiene que ser un dibujo bonito, sino un bosquejo con el cual puedas ayudar a tu compañero. Procura marcar con su nombre los objetos que dibujes o si lo deseas puedes indicarnos cómo se denomina cada objeto para marcarlo y finalmente ubica el sitio donde se encuentra el norte de tu mapa. Cuentas con un tiempo de 20 minutos para realizar tu dibujo, pero si acabas antes nos lo puedes entregar".

Una vez el niño concluía su mapa el observador realizaba una rápida entrevista para determinar el nombre de los objetos dibujados y los referentes ambientales a los que estaban asociados. Igualmente, se procuraba identificar si entre dichos objetos graficados el niño había introducido relaciones de distancia o ubicación e incluso si los trazos realizados tenían la intención de establecer conexiones entre ellos. El entrevistador entregaba los mapas con sus anotaciones para que dos investigadores clasificaran los mapas por consenso.

Una vez terminada la entrevista se agradeció la participación de los niños y se le manifestó que su dibujo estaría expuesto en un lugar de la universidad para que ellos los pudieran verlo y reconocer su dibujo.

Los mapas cognitivos fueron clasificados, por parte de los investigadores, con base en un criterio que es el número de las coordinaciones gráficas. Se consideró que el mapa egocéntrico es aquel en el cual los componentes carecen de coordinación entre elementos dibujados, es decir, de la presencia de un elemento que integre dos elementos claramente diferenciados. Los mapas semicoordinados son aquellos en los cuales aparecen coordinados entre dos elementos. Mapas abstractos o coordinados en los que se presentan más de dos conexiones gráficas o coordinaciones entre objetos dibujados. 


\section{Resultados}

Los dibujos de los niños entre 4 y 6 años

En los mapas de niños de 4 años era particularmente notorio el dibujo con formas de difícil comprensión para otros observadores. El egocentrismo se hizo manifiesto en una estructura gráfica anárquica, pues los niños suponían que cualquier persona podía comprender su composición. Con frecuencia se mostraban disgustados y desconcertados por las preguntas del investigador; eran persistentes en la transparencia de su mapa a los ojos de cualquier otro.

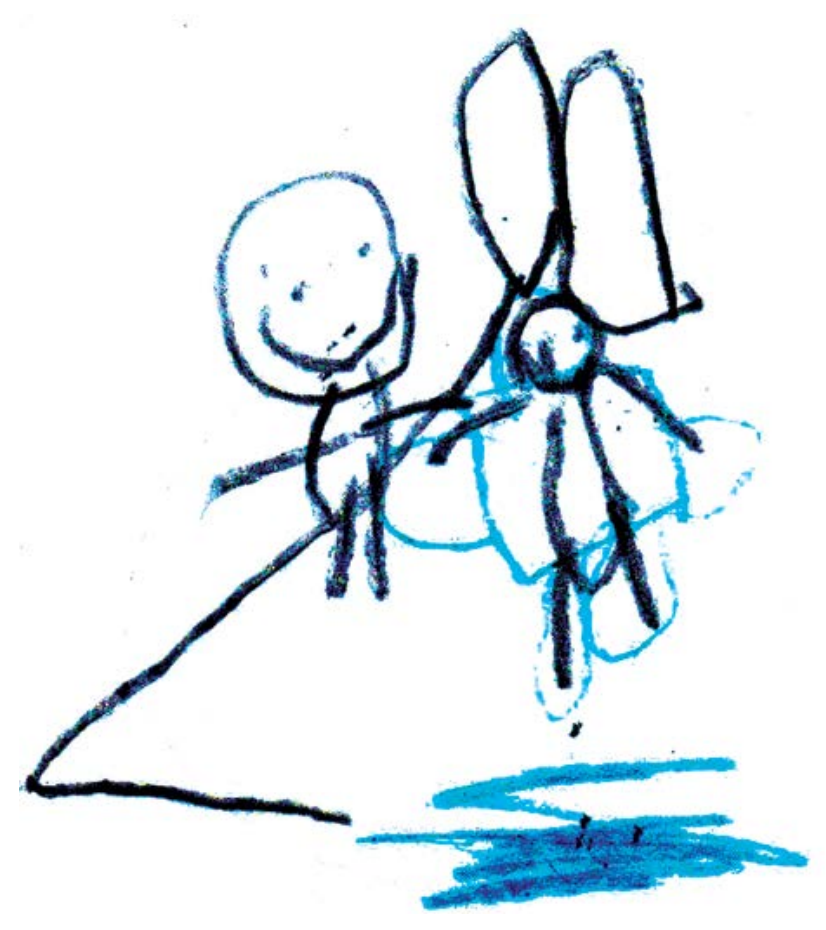

Figura 1. Mapa de niño de 4 años.

El niño afirmó que se graficaba a sí mismo acompañado de su padre a la salida del salón de música. En la parte inferior aparece dibujado un canal de agua al que denomina como "piscina" hacia la cual se dirigen en descenso por las escaleras.

La tendencia a dibujar elementos caracterizados por su apariencia sensorial es representativa de los niños con 4 años de edad. Los objetos graficados son caracterizados por sus propiedades físicas más notorias como su forma o contorno.

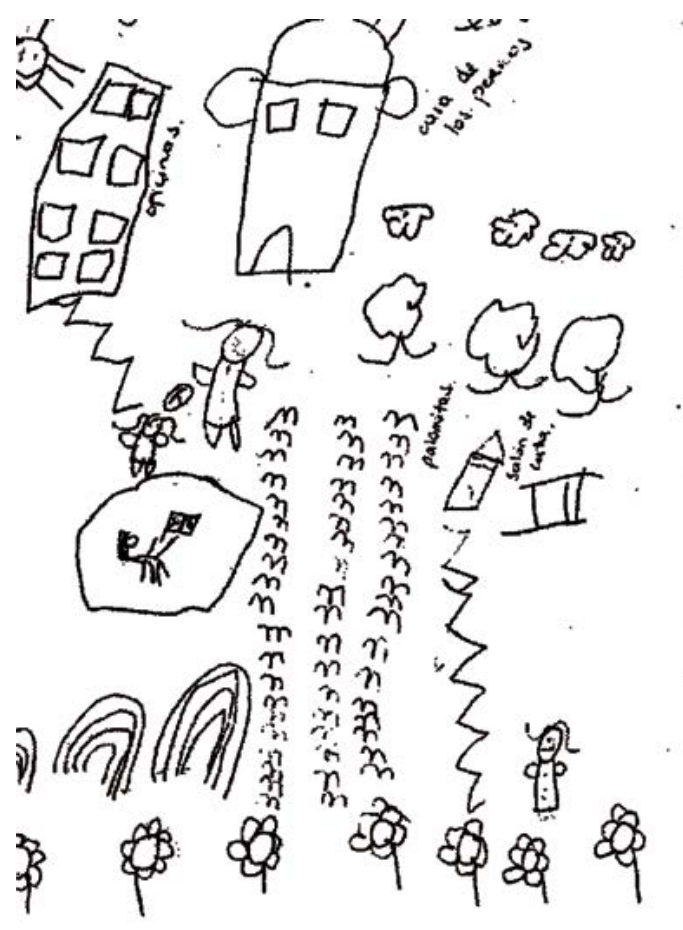

Figura 2. Mapa de una niña de 4 años.

La niña manifestó que en el sector había muchas "palomitas", árboles y flores, junto con niños que estudian y juegan. Mencionó la importancia del edificio de oficinas, donde trabaja su madre ubicado al lado izquierdo superior de la imagen, quien baja por unas escaleras para recogerla de su salón de clases. También resaltó la importancia que tiene para ella la casa de los perros ubicada en la parte superior central de la imagen. Resulta llamativo el tamaño de esta casa con el del edificio cercano. El mapa muestra un conjunto de elementos aislados, no conectados ni radiales como podría ser un mapa. La niña pinta aquello que le gusta del lugar, como las palomas. Claramente este es un mapa egocéntrico.

\section{Los dibujos de los niños de 6-8 años}

La percepción de los niños en esta etapa (6-8 años) se caracterizó, también, por su dimensión sensorio-motriz. Los objetos percibidos son aquellos que ofrecen la oportunidad de ser manipulados. En igual sentido, resultan Ilamativas aquellas experiencias sociales en las que los infantes pueden tomar protagonismo. 


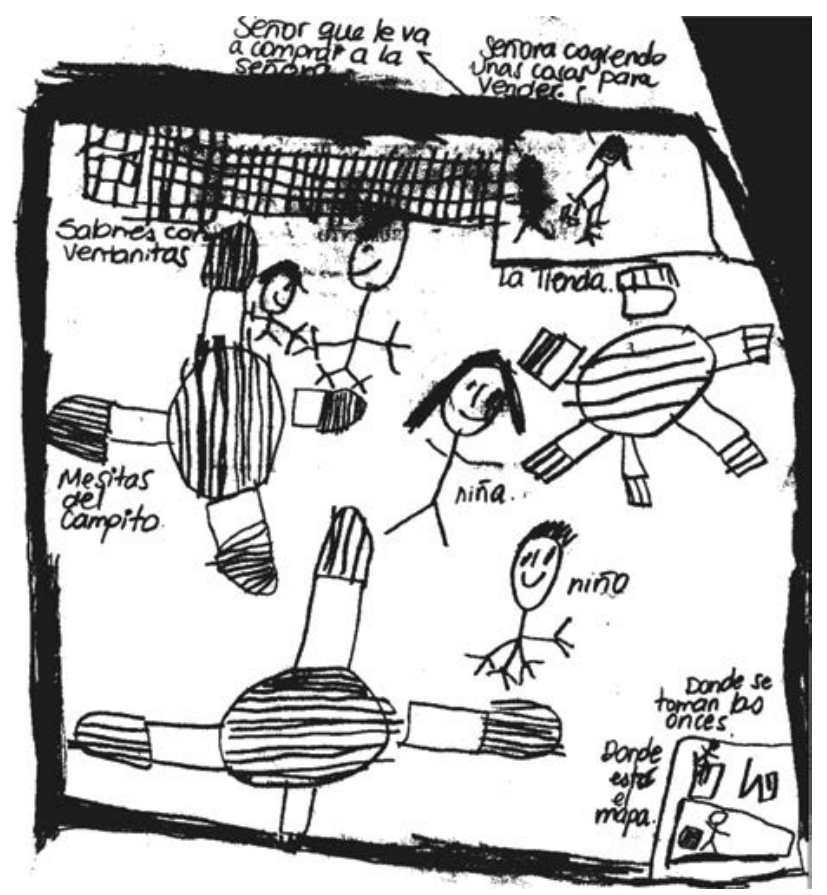

Figura 3. Mapa de niño de 6 años estudiante de música

Resulta interesante la importante presencia de figuras humanas en interacción social a la hora del recreo, así como la presencia de objetos manipulables como mesas y sillas. En la parte superior derecha de la imagen aparece un recuadro con la imagen del niño en proceso de compra de comestibles en la tienda. El énfasis en la ejecución de la compra demuestra el gusto de los niños por representar acciones motrices y sociales. Los objetos manipulables como las mesas, sillas, los comestibles ofrecidos por la tienda fueron dibujados por muchos niños y se hicieron presentes en otras edades mayores. Los niños discriminan aquellos objetos que ofrecen oportunidades de interacción motriz y pueden articularse a sus actividades lúdicas.

En general, se graficaron situaciones relacionadas con el periodo del recreo, momento de integración con otros niños a través del juego y la sensación de esparcimiento. En los dibujos de este periodo existe un amplio contraste entre la zona de recreo, descrita con profundidad por los niños, en relación con las actividades académicas. A la altura del séptimo y octavo año aparecieron mapas interesados en describir el interior de los salones de clase, con sus instrumentos musicales, pupitres, etc. Los mapas describieron una tendencia a reflejar aquellos elementos ambientales con los cuales pueden interactuar de manera espontánea y voluntaria. La expectación de encontrar en el entorno objetos que se presten a la exploración motriz desempeña un papel de primordial importancia dentro de la producción gráfica.

El componente lúdico de los eventos dibujados caracteriza esta etapa. En este periodo evolutivo aparecen importantes rasgos preceptúales: el tamaño y la altura como elemento predominante en los objetos dibujados. En el dibujo se incluyen formas geométricas elevadas que designan puertas, muros y edificaciones en general. Se puede interpretar este hecho como un intento de clasificación y organización del ambiente con base en ciertos atributos de los objetos. En términos piagetanos, se trata de un intento por superar la anarquía del egocentrismo. En el periodo de 4 a 7 años los objetos tenían igual valor. Aquellos elementos Ilamativos a la percepción eran introducidos en el dibujo, sin mayor cuidado por el manejo de la distancia y la ubicación. En igual sentido, los niños buscan en el ambiente elementos de contrastación como el edificio más alto o que "puede llegar hasta el cielo o al sol", el más "gordo" o más flaco, el más colorido, etc.

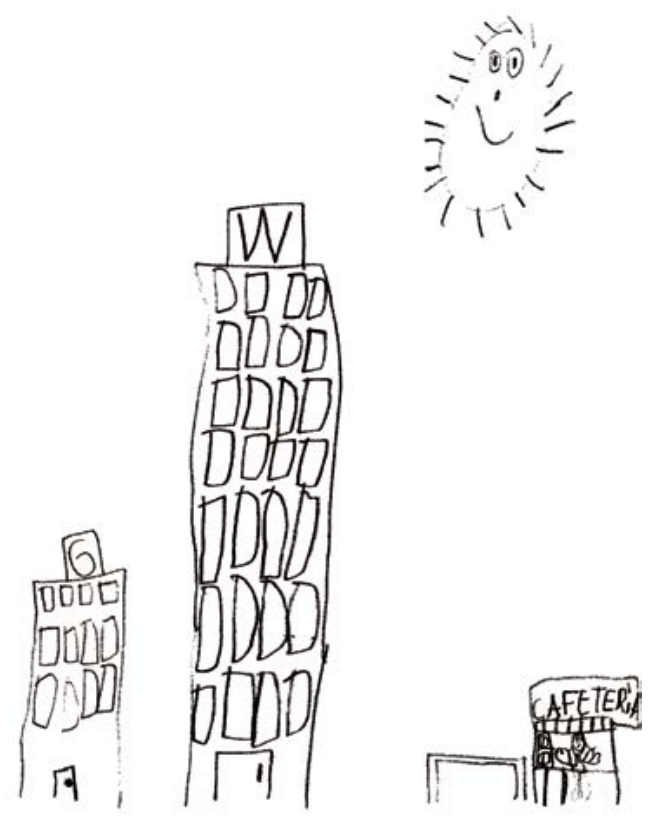

Figura 4. Mapa dibujado por un niño de 8 años estudiante de música. Resulta notable el contraste de los rascacielos con la diminuta cafetería del costado derecho, la cual contiene la figura humana del vendedor, cercana a una vitrina. 
Los objetos no se imponen, si no es el niño quien busca atributos en los objetos para adjudicarles valor superlativo. La percepción del tamaño, la forma y el volumen adquieren gran significado en virtud de su deseo de comparar. El niño transfiere al mundo atributos humanos. Así, por ejemplo, puede clasificar como triste o alegre un edificio, $\mathrm{O}$ sentir pesar por una choza que se siente sola y apabullada en medio de los rascacielos. El concepto de escala humana adquiere su máxima preponderancia. Podemos acudir a nuestros propios recuerdos para valorar el profundo significado que tiene la idea de la casa en el árbol hecha del tamaño de un niño, o el gusto por las carpas y casas para niños. Los objetos acordes con su estatura le resultan agradables por su condición de ser susceptibles a la manipulación. En contraste, los objetos elevados o desproporcionados en función del tamaño infantil aparecen como inalcanzables y poderosos.

Adicionalmente, los mapas cognitivos del periodo exhiben objetos texturados como escaleras, caminos empedrados, al igual que el enrejado de las ventanas o de las baldosas del suelo. La importancia de las superficies terrestres refleja el interés de los niños por crear un plano imaginario sobre el cual depositar los objetos.

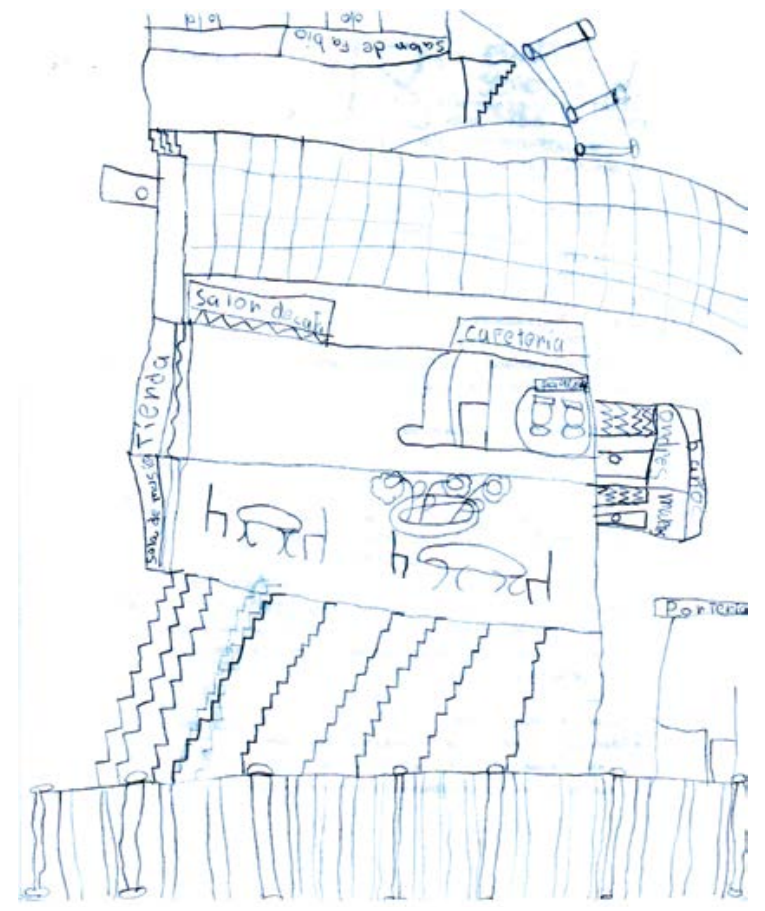

Figura 5. Mapa dibujado por un niño de 7 años y medio estudiante de música.
La parte inferior de la imagen representa las rejas metálicas de la zona de ingreso a la universidad. Las líneas paralelas en zigzag simbolizan el conjunto de escaleras que llevan al sector de estudios musicales. Una plaza presenta incorporados salones circundantes, baños, la tienda, al igual que los detalles de mesas, sillas y flores. Finalmente, el enrejado superior representa las tejas de barro del edificio.

El interés por las texturas terrestres configuradas por formas geométricas que se reproducen, como los empedrados o losas, muestra un intento de agrupar espacialmente los objetos en orden, secuencia y continuidad. Las texturas adquieren su virtud de conjunto gracias a la capacidad de realizar una integración entre parte-todo. El dominio sobre formas geométricas simples hace posible la comprensión del paisaje urbano como la reiteración de un elemento muy representativo como las piedras, las tejas o los vidrios. El gusto por dibujar piedras o losas ordenadas está asociado al manejo de límites, pues en su conjunto presentan contornos y dirección. El intento deliberado por texturar el suelo como un enrejado de baldosas se puede interpretar como el dominio de nociones tales como las de secuencia y continuidad de formas geométricas.

En los niños en esta etapa de 8 a 10 años se observó un importante esfuerzo por realizar agrupamientos. Esto significó la capacidad de clasificar los objetos conforme a la homogeneidad de la forma, el brillo, tamaño, etc. En esta etapa se cuenta con la capacidad de seleccionar aspectos ambientales muy Ilamativos para darle identidad y diferenciarlos claramente de los demás. Se puede afirmar que esta etapa del desarrollo se caracteriza por la capacidad de jerarquizar gráficamente aquello que es objeto de interés para el niño, en virtud de sus ofertas de interacción motriz. Los niños entre 8 y 10 años disfrutan de la tendencia al coleccionismo, a través de objetos como las canicas, piedras, cordeles, etc., las cuales son usadas con frecuencia para desempeñar labores de diferenciación por su color, tamaño, dureza, etc.

La gran atracción de los niños por crear categorías para agrupar los objetos es notable. Con frecuencia, sus juguetes adquieren valor en función de la comparación. Suele suceder que los niños se 
sienten más atraídos por un juguete de otro niño al observar que tiene cualidades que contrastan ampliamente con el suyo. La actividad de comparar los objetos para clasificarlos lleva al niño a buscar en la altura de las edificaciones un criterio de organización. La actividad gráfica refleja claramente el proceso mental de agrupar los objetos bajo una determinada categoría como forma, tamaño, textura, etc. La apreciación de las cavidades y ondulaciones de las superficies adquiere también una presencia notoria en la producción gráfica, pues expresa la expectación de los niños para adelantar acciones físicas. En esta edad se acentúa el gusto por la exploración terrestre. Los niños disfrutan del hecho de abrir agujeros en la tierra o en la arena, fabricar túneles y preparar el terreno para introducir otros objetos.

En esta misma dirección, los niños se encuentran a gusto allí donde pueden introducirse en contextos subterráneos como una gruta, una cava o un túnel. Las rupturas de la superficie terrestre, como los agujeros, provocan la exploración. Basta con recordar el enorme placer de identificar la profundidad de un charco a través de gestos como el brincar dentro de él, así como arrojar piedras a un precipicio para confirmar auditivamente su impresión visual. La identificación de las superficies terrestres ocupa en buena parte las labores de los niños desde temprana edad, pero adquieren principal preponderancia a la altura del séptimo y octavo año. El dibujo infantil ofrece pruebas del interés por identificar el terreno con mayor precisión.

Los mapas cognitivos reflejan un rasgo fundamental: son matrices o herramientas de planificación para las acciones que se van a ejecutar. Cada elemento gráfico denota la expectación de los niños de interactuar con el ambiente, con base en sus propios intereses y expectativas. En este caso, los niños plasman su interés por los desplazamientos motrices y los contenidos ambientales que los hacen posibles, como el relieve de su territorio.

Los dibujos de los niños entre los 9 y 14 años Los dibujos de esta edad se caracterizan por la presentación de una mayor cantidad de objetos de diverso orden, todos ellos incluidos dentro de un plano cartográfico. En primer lugar, aparece un rasgo sobresaliente: la adopción de una perspectiva aérea a la manera de una vista satelital. El cambio de perspectiva espacial es un hecho determinante, pues los objetos dejan de ser considerados desde el punto de vista de la impresión causada sobre el observador. Adquiere mayor importancia la referenciación de cada elemento y su ubicación definida dentro de un plano cartográfico. Surge con gran frecuencia el uso de convenciones gráficas como el uso de flechas o formas geométricas simples acompañadas de denominaciones verbales como el nombre de un barrio encerrado en un círculo.

En este periodo desaparece lentamente la tendencia a la anarquía de elementos gráficos. Los dibujos tienden a agrupar los objetos por cualidades prominentes como su pertenencia a una determinada locación, como puede ser la inclusión de un edificio dentro de un conjunto residencial. Los niños muestran un particular interés por mostrar vías de acceso a las edificaciones. Los mejoramientos de las condiciones subjetivas de la orientación se ven reflejados en la estructuración gráfica. Los caminos muestran rutas de traslado entre diferentes sectores, con especial énfasis en el manejo de escaleras y superficies lisas. La ampliación del campo perceptual es notoria. Los niños dejan de dibujar las zonas más inmediatas a su sitio de mayor estadía para dar lugar a otros sectores de vital importancia como las zonas de servicios. Así, aparecen como elementos importantes el sector de la biblioteca, edificios circundantes, parqueaderos, así como un permanente contraste entre sitios edificados y áreas verdes.

Resulta particularmente Ilamativo el hecho de que el dibujo de este periodo se caracteriza por su interés en comunicar con claridad las formas de movilizarse por el territorio graficado. Los niños toman en consideración la interpretación que otros le pueden dar a sus imágenes. La inclusión de las sendas como elemento integrador de edificios hace de los mapas instrumentos legibles. Los objetos se distribuyen dentro de una pauta de continuidad en la que los individuos pueden identificar el inicio de un recorrido y un punto de llegada. 


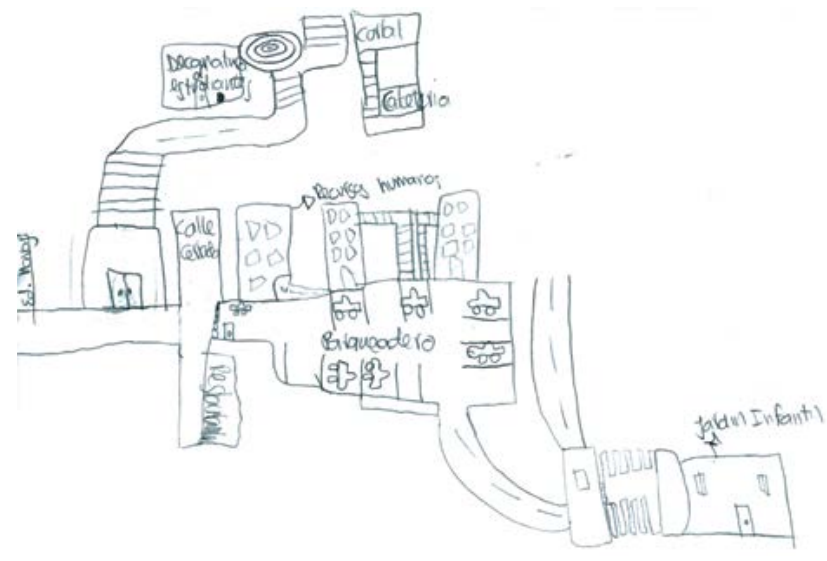

Figura 6. Mapa dibujado por una estudiante del programa de deportes de 13 años de edad. La imagen presenta una hoja de ruta para movilizarse por diversos sectores de la universidad, a través de un conjunto de sendas.

Los mapas del periodo preadolescente reflejan el interés por conectar los elementos dibujados. Se hace evidente el deseo de introducir componentes que enriquezcan la imagen gráfica con detalles que la presentación de imágenes configurados a la manera de mapas de ruta. En ellos se señalan diferentes estaciones y se realizan estimaciones gráficas sobre la distancia de un lugar a otro.

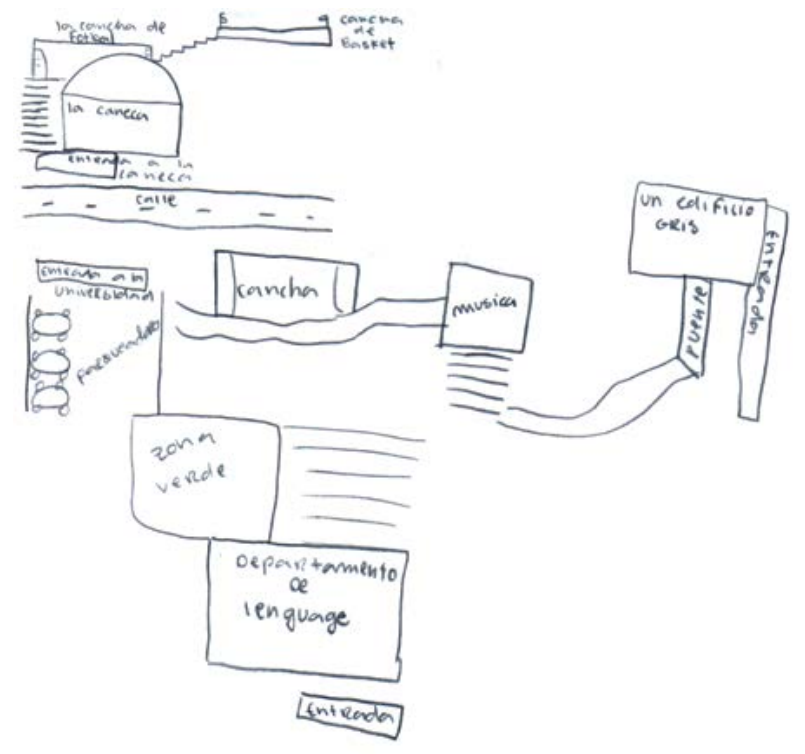

Figura 7. Mapa dibujado por una estudiante de música de 11 años. La hoja de ruta resalta la presencia de sendas texturadas, que conectan sectores claramente determinados por formas geométricas. Los conjuntos de líneas paralelas repetidas designan las escaleras y su extensión.

Los mapas de este periodo reflejan una mayor libertad de movimiento y exploración activa del entorno. La capacidad de representar objetos se produce en un campo mental mucho más amplio. El radio de la percepción se extiende a objetos distintos a los del propio territorio (sector de salones de clases de música). La orientación espacial es cada vez más recursiva. La dependencia de un solo sector como elemento central para orientarse sede ante la búsqueda de otros sectores. A lo largo del proceso de dibujo los niños aclaraban que esta era su ruta preferida, pero asumían que podrían hacerse desplazamientos por otros sectores.

La opcionalidad es un rasgo cada vez más notorio. Los niños asumen que su forma de ordenar el ambiente es el producto de su propia perspectiva. Asumen la posibilidad de crear otras alternativas de desplazamiento, pero dibujan la que tienen más claramente definida. El hecho más Ilamativo en esta etapa es la tendencia a la estructuración de un plano visual en el que se demuestra un mayor dominio sobre la capacidad de prescindir de la apariencia sensorial de los objetos y sus detalles, como los edificios con puertas y ventanas. El mayor dominio sobre la capacidad de clasificar lleva a un agrupamiento cada vez más exitoso de los sectores hasta el extremo de exhibir la presencia de barrios representados con formas geométricas simples y acompañados de denominaciones escritas.

En términos generales, en este periodo se logran significativos avances en la superación de los rasgos egocéntricos más profundos, entre ellos: la dependencia de la apariencia de estímulos aislados, la incapacidad para realizar conexiones entre diferentes zonas ambientales y, especialmente, la consolidación de una visión paisajista, global o "holista".

\section{Conclusiones}

La presente investigación se propuso estudiar la forma en que los niños se orientan en espacios urbanos y sus principales recursos cognoscitivos para interactuar con el ambiente. Se usó la estrategia metodológica de mapa cognitivo como recurso para identificar los referentes espaciales u objetos urbanos que le permiten ubicarse espacialmente.

La hipótesis investigativa se basó en los aportes del constructivismo genético de corte piagetano, en 
la que se asume que los niños a menor edad tienen una representación mental "egocéntrica", analítica y fragmentaria del ambiente. En esta misma, aparecen elementos ambientales desarticulados e inconexos y adjudica que la tendencia del desarrollo cognitivo radica en ordenar las imágenes mentales saturadas de información dispersa para darles relaciones de orientación, distancia, tamaño, etc.

Los resultados arrojados por la aplicación de mapas cognitivos demuestran que los dibujos infantiles en niños de muy temprana edad, como aquellos de 4 a 6 años, guardan características egocéntricas; pues dibujan objetos ligados a su experiencia sensorial más inmediata y llamativa sin poder acceder a otros elementos menos frecuentes o distantes de su desempeño sensorio-motriz.

La persistencia del egocentrismo es sumamente notable, en niños de edad escolar entre los 8 y 10 años, y la aparición de las conexiones gráficas tan solo se produce en niños de edades cercanas a la adolescencia. La teoría piagetana ofrece un interesante marco de referencia para interpretar los mapas cognitivos, pues muestra a las claras que la representación mental del ambiente urbano sigue un proceso que va de las formas más simples de la percepción como son la captación de los estímulos visuales Ilamativos que abarcan la atención del niño por su brillo, profundidad, tamaño, etc., y dejan al niño deslumbrado por su apariencia.

La experiencia del niño en edad preescolar y escolar es la de una persona que requiere de apoyo para realizar enlaces entre los diferentes componentes de la ciudad. Basta que un niño camine por la calle y vea una mariposa o un ave que se le acerca para que pierda de vista el conjunto del recorrido y se centre en un solo evento que determina su interpretación del ambiente. Los niños se tropiezan al ver un objeto alado o flotante como un globo, pues su atención se dispersa y de repente el globo flotante o el ave ocupa el valor de un universo propio sobre el cual el niño vuelca todo su interés para examinar su textura, su color, su peso, su sabor, etc., sin poder conectar los objetos. Hasta tanto, el niño no supera su curiosidad por los elementos más atractivos del ambiente y comprueba sus condiciones estimulantes no puede pasar a la identificación de otras cosas.
La lentitud del desarrollo cognitivo en materia de orientación espacial resulta sumamente ilustrativa en materia educativa, pues no se puede esperar que el niño en edades tempranas entienda la ciudad con solo recorrerla con cierta frecuencia. Los niños se desorientan con facilidad porque el mundo les resulta muy novedoso y desconcertante. La lentitud del desarrollo en materia de cognición ambiental hace necesaria la paciencia del adulto y su comprensión para entender las facultades del desarrollo infantil. Con frecuencia, los adultos se disgustan porque un niño de edad preescolar o escolar se pierde o se distrae, cuando se le pide que vaya a la tienda de la esquina para hacer un mandado. Los niños suelen ser tratados como sujetos ineptos en materia ambiental, cuando en realidad están en medio de su camino de construir imágenes mentales cada vez más consolidadas, en la que cada objeto tenga verdadera identidad para acceder a la esfera de las conexiones ambientales.

La teoría de Piaget se hizo comprobable en materia de cognición urbana infantil, pues los mapas cognitivos mostraron un carácter constructivista. La primera etapa de la orientación espacial es la construcción de imágenes ambientales, cuyo punto de partida son los pequeños descubrimientos del mundo circundante como la zona donde vuelan las palomitas. La experiencia del niño radica en utilizar sus pequeños descubrimientos ambientales para realizar nuevas aventuras de aproximación a otros objetos, como ubicar las palomitas y los pupitres en el entorno del salón de clases. La reiteración del niño en el esfuerzo por ampliar sus descubrimientos lo lleva a reformularse el absolutismo de las primeras impresiones para abrirle camino al interés por la comprensión de nuevos elementos atrayentes y significativos.

El mapa cognitivo ha sido una herramienta de vital importancia en esta investigación por facilitar la expresividad infantil en materia ambiental. Los infantes participantes del estudio se mostraron motivados, pues asumían el dibujo como una actividad divertida en la cual querían perseverar. Con frecuencia, los niños más pequeños le pedían al investigador más hojas para dibujar y solicitaban instrucciones con preguntas como: "¿ahora qué dibujo? ¿Puedo hacer otro dibujo para mi mamá?". 
La espontaneidad de la actividad gráfica en los niños creaba un ambiente de distensión y confianza con los investigadores, de tal manera que los niños comentaban sus creaciones con gran fluidez. En los niños en edad puberal era frecuente el gran cuidado por la calidad del dibujo, pues procuraban que las gráficas tuvieran cierta forma geométrica y simetría. Gustaban de acompañar cada objeto dibujado con el nombre del referente espacial al cual se refería y con frecuencia pedían más tiempo para seguir perfeccionando su mapa. El grafismo infantil fue un interesante y agradable medio de interacción entre investigadores y participantes por el hecho de fomentar la voluntariedad de los niños dentro del estudio, las formas de comunicación respetuosas y amables, al igual que el entorno ético que debe caracterizar el trabajo sobre la cognición ambiental infantil.

\section{Referencias}

Aragonés, J. I. y Amérigo, M. (1998). Psicología ambiental. Madrid: Pirámide.

Caballero, A. (2002). Desarrollo de la representación espacial. EduPsykhé: Revista de Psicología y Psicopedagogía, 1(1) 45-67.

Downs, R. M. y Stea, D. (1973). Image and Environment: Cognitive Mapping and Spatial Behavior. Chicago, IL: Aldine.

Foster, S., Villanueva, K., Wood, L., Christan, H. y Giles Corti, B. (2014). The impact of parents fear of stranger and perceptions or informal social control on children's independent mobility. Health \& Place, 26, 60-68. https://doi.org/10.1016/j.healthplace.2013.11.006

Gallego, L. M., Gallego, D., Arboleda, A., Garcés, L. y Sepúlveda, J. (2017). La influencia de la psicología ambiental en el contexto de la educación en Colombia: el caso del centro de Medellín. Producción + Limpia, 12(1) 124-132. Recuperado de http://repository.lasallista.edu. co:8080/ojs/index.php/pl/article/view/1380 https://doi.org/10.22507/pml.v12n1a13

García, F. y Peralta, M. P. (2016). Las urbanizaciones multifamiliares cerradas y su entorno urbano: una nueva geografía simbólica en la ciudad de Cali. Eure, 42(126),
77-96. Recuperado de https://scielo.conicyt.cl/scielo.php?script=sci_arttext\&pi$\mathrm{d}=$ S0250-71612016000200004 https://doi. org/10.4067/s0250-71612016000200004

Goga, N. y Kümmerling-Meibauer (Eds.). (2017). Maps and mapping in children's literature. Landscapes, seascapes and cityscapes. Ámsterdam: John Benjamins Publishing Company. https://doi.org/10.1075/clcc.7

Hart, R. A. y Moore, G. T. (1973). The development of spatial cognition: A review. En R. M. Downs y D. Stea (eds.), Image and Environment: Cognitive Mapping and Spatial Behavior (pp. 246288). Chicago, IL: Aldine.

Jiménez, A. e Infante, R. (2008). Infancia y ciudad en Bogotá. Bogotá: Universidad Distrital Francisco José de Caldas.

Kitching, R. (2015). Cognitives maps. En Neil J. Smelser y Paul B. Baltes (eds.), International Encyclopedia of Social Behavior Science (pp. 79-85). Ámsterdam: Elsevier.

Lázaro, V. (2000). La representación mental del espacio a lo largo de la vida. Zaragoza, España: Universidad de La Rioja, Egido.

Lynch, K. (1998). La imagen de la ciudad. Barcelona: Gustavo Gili.

Marchesi, A. (1983). Conceptos espaciales, mapas cognitivos y orientación en el espacio. Estudios de Psicología, 14/15, 85-92. Recuperado de file://D:/Users/unesco5/Downloads/Dialnet-ConceptosEspacialesMapasCognitivosYOrientacionEnEl-65885.pdf https://doi.org/10.10 80/02109395.1983.10821355

Miao, M., Zeng, L., y Weber, G. (2017). Externalizing cognitive maps via map reconstruction and verbal description. Universal Access in the Information Society 16(3), 667-680. Recuperado de https://link.springer.com/article/10.1007/ s10209-016-0497-5

Montello, D. (2015). Spatial cognition. Neil J. Smelser y Paul B. Baltes (eds.), International Encyclopedia of Social Behavior Science (pp. 111-115). Ámsterdam: Elsevier.

Moore, G. T. (1974). The development of environmental knowing: An overview of interactional-constructivist theory and some data 
within-indivudual development variations. En D. Canter y T. Lee (eds.), Psychology and the Built Enviroment. Nueva York: Halstead Press.

ONU-Habitat (Programa de las Naciones Unidas para los Asentamientos Humanos) (2012). Estado de las ciudades de América Latina y el Caribe 2012. Rumbo a una nueva transición urbana. ONU-Habitat. Recuperado de https:// www.zaragoza.es/contenidos/medioambiente/ onu//newsletter12/887_spa.pdf

Oviedo, G. L. (2002). El estudio de la ciudad en la psicología ambiental. Revista de Estudios Sociales (RES), 11, 26-34. Recuperado de https:// journals.openedition.org/revestudsoc/27485

Oviedo, G. L. (2006). La orientación espacial de los niños en el espacio físico de la Universidad de los Andes. Bogotá: Centro de Estudios Socioculturales e Internacionales CESO, Facultad de Ciencias Sociales Universidad de los Andes.

Piaget, J, (1973). La representación del mundo en el niño. Madrid: Morata.

Proshansky, H. M. (1984). La psicología ambiental y el mundo real. Cuadernos de Psicología, 6(2), 126-180.

Rissotto, A. y Tonucci, F. (2002). Freedom of movement and environmental knowledge in elementarry school children. Journal of Environmental Psychology, 22(1-2), 65-77. https:// doi.org/10.1006/jevp.2002.0243

Rizo, L., Gutiérrez, F. y Granada, H. (2004). Percepción, conocimiento y valoración del ambiente físico y social de la universidad del Valle sede Meléndez en u grupo de estudiantes y su influencia en el comportamiento ecológico responsable. Psicología desde el Caribe. 14: 173-221.

Roncancio, C., Minsnaza, P. y Prieto, F. (2015). Mortalidad en menores de cinco años debida a lesiones causadas por el tránsito, Colombia, 2005-2009. Biomédica, 35, 306-313. Recuperado de https://revistabiomedica.org/index.php/ biomedica/article/view/2554/2838

https://doi.org/10.7705/biomedica.v35i3.2554

Sotelo, V. y González A. (2006). Análisis de seguimiento por denuncias por presuntos actos sexuales abusivos cometidos contra niños, niñas y adolescentes. Universitas Psychologica, 5(2), 397-418. Recuperado de http://pepsic. bvsalud.org/scielo.php?script=sci_arttext\&pi$d=$ S1657-92672006000200015

Tonucci, F. (1983). Ciudades a escala humana: la ciudad de los niños. Revista de Educación, número extraordinario, 147-168.

Tonucci, F. (1997). L ciudad de los niños. Madrid: Fundación Germán Sánchez Ruipérez.

Tonucci, F. (2009). La soledad de los niños. Buenos Aires: Losada.

Vidar, U., Vitaro, F., Brendgen, M., Bekkhus, M. y Borge, A. (2017). Time spent outdoors during preschool: Links with children's cognitive and behavioral development. Journal of Enviromental Psycholory, 52, 69-81. https://doi.org/10.1016/j.jenvp.2017.05.007 